\title{
Pembuatan Sistem Dashboard Akreditasi Institusi Perguruan Tinggi Standar 4 Berbasis Key Performance Indicator
}

\author{
Abu Abbas Mansyur ${ }^{*}$, Hariyadi $^{2}$, Agus Eko Minarno ${ }^{3}$ \\ 1,2,3 Teknik Informatika/Universitas Muhammadiyah Malang \\ abbasmansyur96@gmail.com ${ }^{* 1}$, hariyady@gmail.com², agoes.minarno@gmail.com³
}

\begin{abstract}
Abstrak
Sistem Dashboard sangat dibutuhkan dalam proses Akreditasi Institusi Perguruan Tinggi, system dashboard mempermudah proses monitoring sebuah kinerja yang sedang dilaksanakan. Proses penilaian akreditasi menggunakan indicator-indicator tertentu untuk menandakan kondisi suatu proyek, proses akreditasi memerlukan datavdan informasi dari semua pihak-pihak yang berkaitan dengan perguruan tinggi. Indicator-indicator yang digunakan bersumber dari BAN-PT berdasarkan data dari setiap komponen yang ada di perguruan tinggi. Data dan informasi tersebut harus sesuai dengan kondisi internal yang ada di perguruan tinggi sekarang ini. Karena nantinya hasil dari penelitian ini digunakan untuk proses evaluasi akreditasi di asa yang akan dating. Sehingga kedepannya suatu perguruan tinggi bias mempertahankan ataupun meningkatkan nilai akreditasi.
\end{abstract}

Kata Kunci: Sistem Dashboard, AIPT, Key Performance Indicator

\begin{abstract}
Dashboard system is needed in the Higher Education Institution Accreditation process, the dashboard system facilitates the process of monitoring a performance that is being implemented. The accreditation assessment process uses certain indicators to indicate the condition of a project, the accreditation process requires data and information from all parties related to tertiary institutions. The indicators used are sourced from BAN-PT based on data from each component in the tertiary institution. The data and information must be in accordance with the internal conditions that exist in universities today. Because later the results of this research will be used for the accreditation evaluation process in the future. So that in the future a tertiary institution can maintain or increase the value of accreditation.
\end{abstract}

Keywords: Dashboard System, AIPT, Key Performance Indicator

\section{Pendahuluan}

Dashboard merupakan tampilan panel yang dibuat dengan software komputer dengan tujuan menampilkan sebuah informasi yang mudah dibaca dan dipahami. System dashboard adalah alat untuk menyajikan kebutuhan informasi. Dashboard adalah alat bantu kontrol untuk mengidentifikasikan jalannya proses bisnis, bisa berupa indikator-indikator tertentu seperti penggunaan warna tertentu yaitu merah,hijau atau kuning yang melambangkan suatu kondisi suatu proyek [1]. Dashboard pada penelitian ini digunakan untuk mengidentifikasi kinerja dari tujuh standar akreditasi [2]. Dashboard adalah sebuah alat yang digunakan untuk mengevaluasi sebuah proses yang sedang berjalan,monitoring kinerja, dan memprediksi kondisi di masa yang akan datang [3].

Akreditasi adalah bentuk penilaian (evaluasi) mutu dan kelayakan institusi perguruan tinggi atau program studi yang dilaksanakan oleh organisasi atau badan di luar perguruan tinggi [4]. Akreditasi menjadi bagian yang tidak dapat dipisahkan dari manjemen pendidikan. Aktivitas dan prosesnya mengarah ke evaluasi internal dan eksternal agar mendapat sertifikasi yang dilaksanakan oleh lembaga tertentu. Proses akreditasi harus diikuti oeh semua elemen dalam universitas. Agar akreditasi yang didapatkan nantinya bisa menjadi lebih baik.

Standar tenaga kependidikan atau sumber daya manusia (SDM) harus ditingkatkan oleh perguruan tinggi secara terus-menerus dari waktu ke waktu sehinggga SDM bisa berkembang secara berkelanjutan. Sumber daya manusia sangat mempengaruhi sebuah akreditasi perguruan tinggi. Bagaimana sebuah perguruan tinggi memperlakukan dan memberikan layanan kepada sumber daya manusia. yang meliputi dosen dan tenaga kependidikan yang mencangkup 
pustakawan, laboran, teknisi dan tenaga administrasi yang bertanggung jawab atas pencapaian mutu keseluruhan program tri darma perguruan tinggi. Perguruan tinggi merencanakan dan melaksanakan program-program peningkatan mutu dosen dan tenaga kependidikan yang selaras dengan kebutuhan, untuk mewujudkan visi dan melaksanakan misinya.

Key Performance Indicator adalah kumpulan dari beberapa metric finansial maupun non finansial yang digunakan untuk menentukan dan mengukur kemajuan sebuah sasaran organisasi, KPI digunakan pada Business intelligence untuk mengukur keadaaan kini sebuah bisnis dan menentukan apa yang harus dilakukan kedepannya [5]. KPI sangat penting dalam sebuah organisasi karena KPI sendiri mengukur sebuah aktivitas yang sulit dicapai.

Dari penjelasan diatas maka penelitian ini akan membuat system dashboard untuk memonitoring proses akreditasi di Universitas Muhammadiyah Malang berbasis key performance indicator.

\section{Metode Penelitian}

Metode yang digunakan pada pembuatan system dashboard akreditasi institusi perguruan tinggi standar 4 berbasis key performance indicator adalah menggunakan incremental model, Incremental model dipilih karena dengan menggunakan metode ini kita dapat meminimalisir ketidaksesuaian dalam pengembangan proses perangkat lunak [6], dengan tahapan seperti Gambar 1.

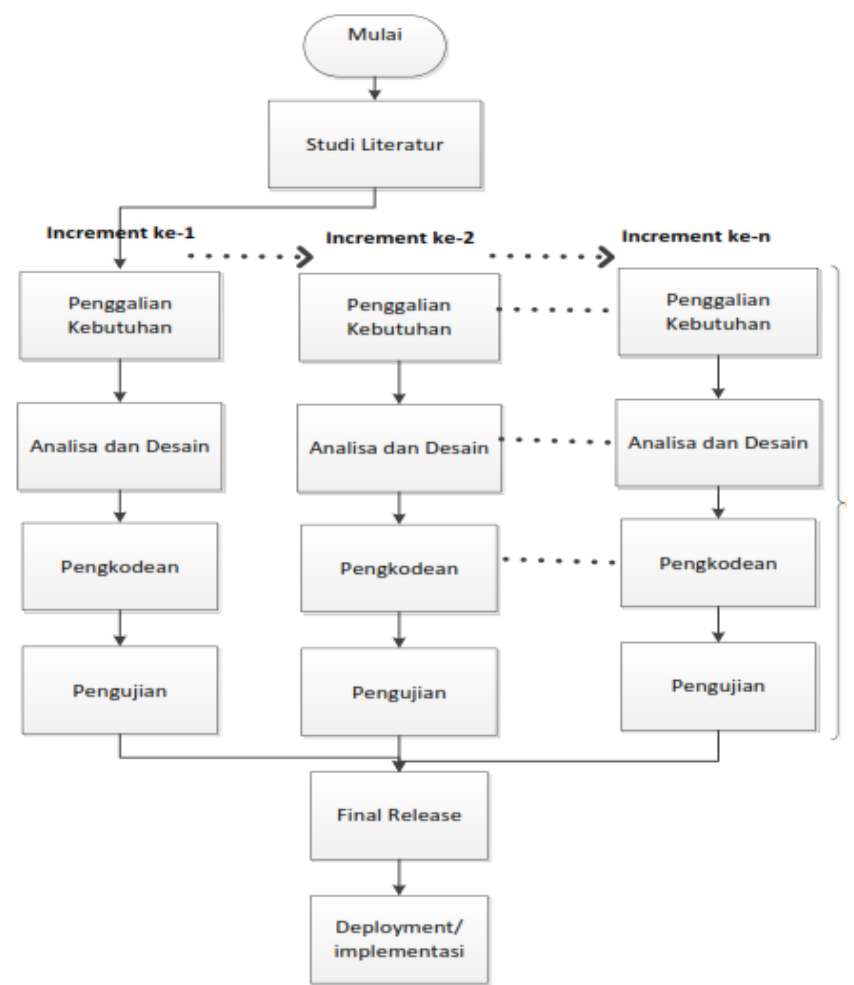

Gambar 1. Alur Metode Penelitian

a) Analysis dan Desain

Analysis yang dilakukan yaitu mengumpulkan beberapa sumber refrensi yang digunakan dalam penelitian ini. Yang berkaitan dengan penelitian-penelitian terdahulu, dan juga dari borang akreditasi yang ada di Buku II Standar dan dari berbagai jurnal lainnya. Proses desain dashboard dimulai dengan penyusunan key performance indicator. Selain itu pembuatan desain mockup akan dibuat,tujuannya agar lebih jelas bagaimana antarmuka dan peletakkan komponenkomponen dashboard yang akan dibuat [7]. Dashboard yang dibuat memiliki fungsi menampilkan kondisi pencapaian indicator tiap fakultas dan program studi.

b) Implementasi

Sistem dashboard akreditasi perguruan tinggi ini dibuat menggunakan Bahasa pemrograman php, Database MySQL dan memakai Framework Cl. 
c) Pengujian

Pengujian dilakukan dengan menggunakan black box testing. Pengujian ini dilakukan untuk menilai apakah system dashboard yang dibuat dapat menyelesaikan permasalahan yang muncul selama ini. Pengujian yang dilakukan dari sisi user interface, pengujian error, dan fiturfitur system [8].

\section{Hasil Penelitian dan Pembahasan}

Pada bab ini akan menjelaskan mengenai hasil dari penelitian dan penjelasan dari beberapa fitur berupa menu yang ada pada setiap operator dan fungsi dari masing-masing fitur pada operator tersebut dan juga pengujian yang sudah dilakukan.

\subsection{Implementasi}

a. Tampilan Login

Pada Gambar 2 adalah tampilan login, dimana masing-masing operator harus memiliki ussername dan password agar bisa masuk ke dalam sistem.

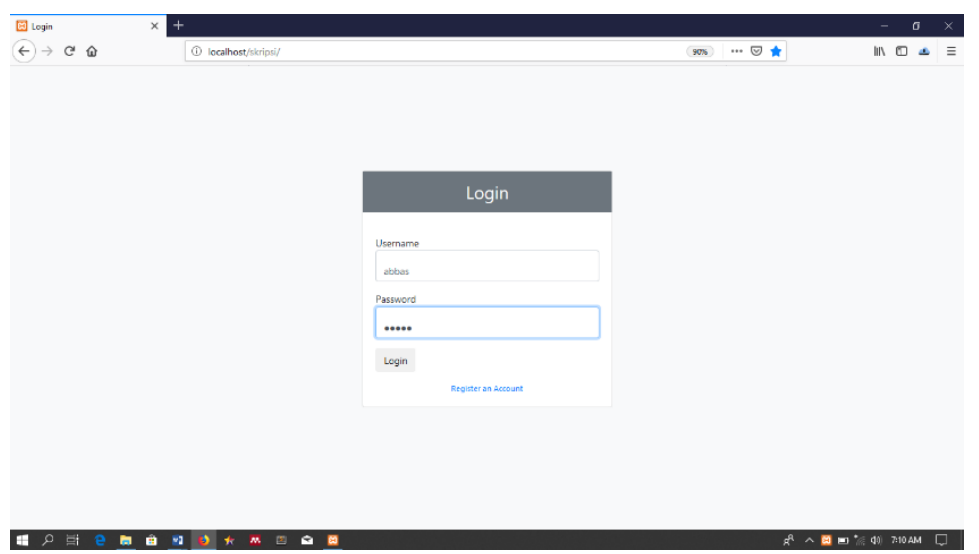

Gambar 2. Tampilan Login

b. Tampilan Kelola Admin

Pada Gambar 3, halaman ini menampilkan kelola data admin, dimana admin bisa mengatur operator apa saja yang bias login atau masuk ke dalam system. Ketika status active maka operator tersebut bisa masuk ke dalam system, begitu juga sebaliknya jika non active maka operator tidak bias login ke dalam sistem.

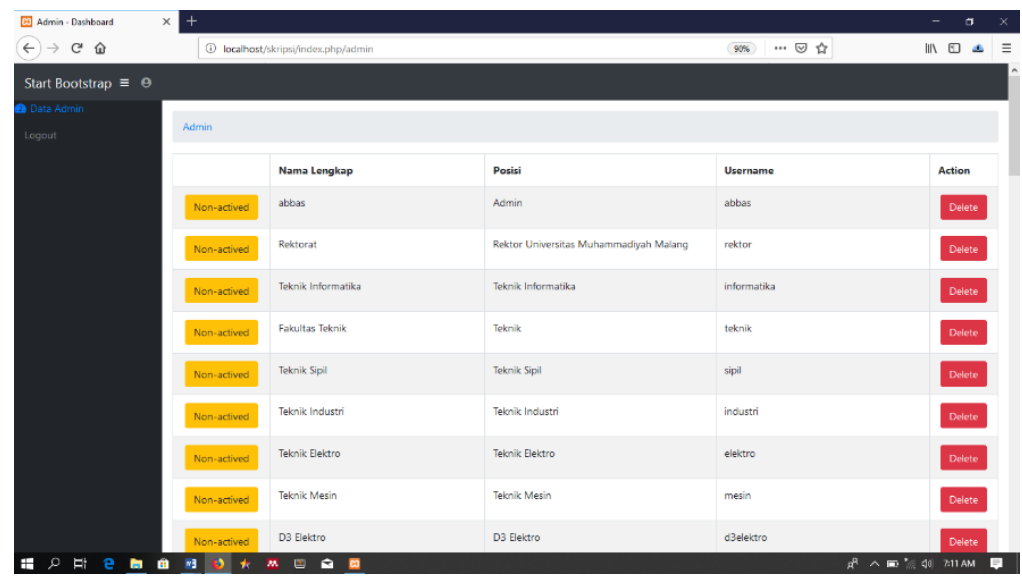

Gambar 3. Kelola Data Admin

c. Tampilan Lihat Dashboard

Pada Gambar 4, halaman Lihat Dashboard ini bisa menampilkan dashboard se-universitas dashboard per fakultas dan juga data borang tiap-tiap program studi.

Pembuatan Sistem Dashboard Akreditasi... Abu Abbas Mansyur, Hariyadi, Agus Eko Minarno 


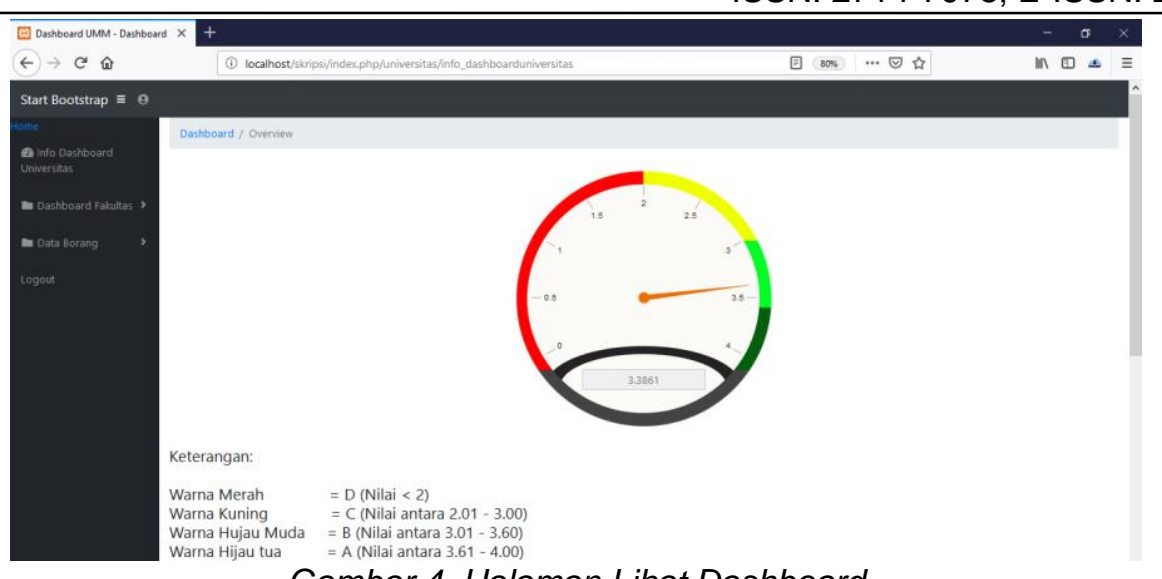

\section{Gambar 4. Halaman Lihat Dashboard}

d. Tampilan Lihat Data Borang

Pada Gambar 5 halaman lihat data borang adalah halaman dimana operator melihat data borang yang telah diupload sebelumnya pada halaman upload data borang.

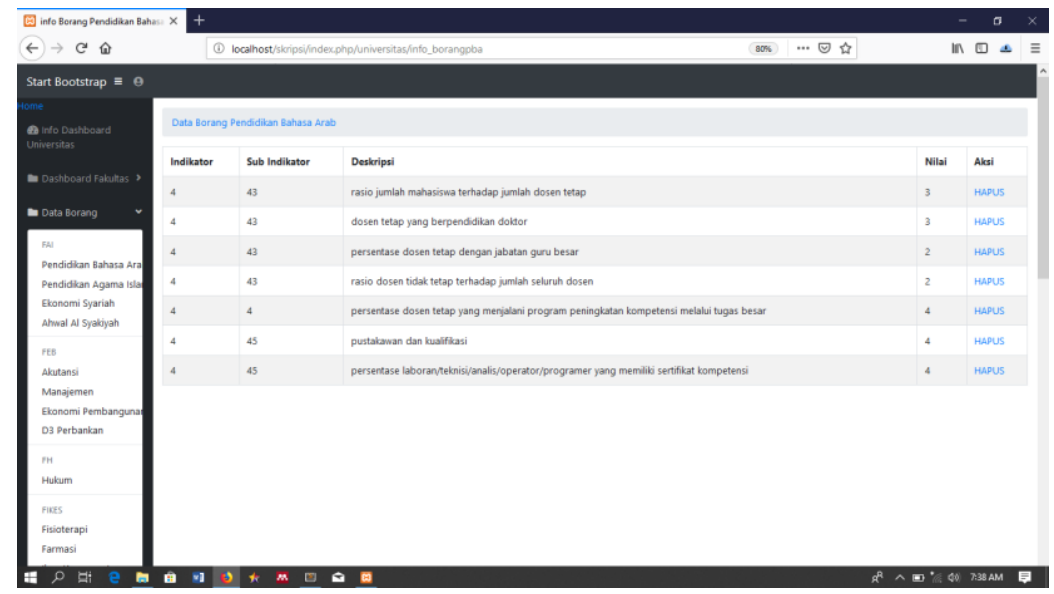

Gambar 5. Lihat Data Borang

\subsection{Pengujian}

Black Box Testing adalah suatu pengujian yang dapat dilakukan pada suatu sistem untuk dapat mengetahui tingkat kesuksesan komponen berupa fitur yang ada pada system tersebut. Dalam Tabel 1, Tabel 2, Tabel 3, Tabel 4, Tabel 5, Tabel 6, Tabel 7, dan Tabel 8 bentuk pengujian ini penguji dapat mengambil suatu kesimpulan dari hasil interaksi yang dilakukan langsung pada sistem.

Tabel 1. Pengujian Halaman Login Admin

\begin{tabular}{cccc}
\hline \multicolumn{4}{c}{ Tujuan: Mengetahui fungsionalitas pada halaman login admin } \\
\hline No & Proses & Hasil yang diharapkan & Status \\
\hline 1 & Login berhasil & Tampil halaman home admin & Success \\
2 & Login gagal & Tampil peringatan username dan password & Success \\
salah & & \\
\hline
\end{tabular}

Tabel 2. Pengujian Pada Halaman Admin

Tujuan: Mengetahui fungsionalitas pada halaman home admin

\begin{tabular}{cccc}
\hline \multicolumn{5}{c}{ Tujuan: Mengetahui fungsionalitas pada halaman home admin } \\
\hline No & Proses & Hasil yang diharapkan & Status \\
\hline 1 & Click button active & Status menjadi active & Success \\
2 & Click button non- & Status menjadi non-actived & Success \\
3 & Click button delete & Akun terhapus & Success \\
4 & Click menu logout & Melakukan logout & Success \\
\hline
\end{tabular}

REPOSITOR, Vol. 2, No. 3, Maret 2020: 305-310 
Tabel 3. Pengujian Pada Halaman Login Prodi

\begin{tabular}{cccc}
\hline \multicolumn{4}{c}{ Tujuan: Mengetahui fungsionalitas pada halaman login prodi } \\
\hline No & Proses & Hasil yang diharapkan & Status \\
\hline 1 & Login berhasil & Tampil halaman home & Success \\
2 & Login gagal & Tampil peringatan username dan & password salah \\
\hline
\end{tabular}

Tabel 4. Pengujian Pada Halaman Prodi

Tujuan: Mengetahui fungsionalitas pada halaman Prodi

\begin{tabular}{cccc}
\hline No & Proses & Hasil yang diharapkan & Status \\
\hline 1 & Click menu "Upload " & Tampil form halaman isi Upload & Succes \\
2 & $\begin{array}{c}\text { Click menu "Tampil } \\
\text { data borang" }\end{array}$ & $\begin{array}{c}\text { Tampil halaman menu tampil data } \\
\text { borang }\end{array}$ & Success \\
3 & $\begin{array}{c}\text { Click menu } \\
\text { "Dashboard" }\end{array}$ & Tampil halaman menu dashboard & Success \\
4 & Click tombol logout & Melakukan logout & Success \\
\hline
\end{tabular}

Table 5. Pengujian Pada Halaman Login Fakultas

Tujuan: Mengetahui fungsionalitas pada halaman login fakultas

\begin{tabular}{cccc}
\hline \multicolumn{4}{c}{ Tujuan: Mengetahui fungsionalitas pada halaman login fakultas } \\
\hline No & Proses & Hasil yang diharapkan & Status \\
\hline 1 & Login berhasil & Tampil halaman home fakultas & Success \\
2 & Login gagal & Tampil peringatan username dan & password salah \\
\hline
\end{tabular}

Tabel 6. Pengujian Pada Halaman Fakultas

Tujuan: Mengetahui fungsionalitas pada halaman fakultas

\begin{tabular}{cccc}
\hline \multicolumn{4}{c}{ Tujuan: Mengetahui fungsionalitas pada halaman fakultas } \\
\hline No & Proses & Hasil yang diharapkan & Status \\
\hline 1 & $\begin{array}{c}\text { Click menu "Info } \\
\text { dashboard fakultas" } \\
\text { Click menu "data } \\
\text { borang prodi" }\end{array}$ & $\begin{array}{c}\text { Tampil halaman dashboard fakultas } \\
\text { Tampil halaman menu data borang }\end{array}$ & Success \\
prodi & Succes \\
3 & Click tombol logout & Melakukan logout & Success \\
\hline
\end{tabular}

Tabel 7. Pengujian Halaman Login Universitas

Tujuan: Mengetahui fungsionalitas pada halaman login universitas

\begin{tabular}{cccc}
\hline \multicolumn{4}{c}{ Tujuan: Mengetahui fungsionalitas pada halaman login universitas } \\
\hline No & Proses & Hasil yang diharapkan & Status \\
\hline 1 & Login berhasil & Tampil halaman home universitas & Success \\
2 & Login gagal & Tampil peringatan username dan & Success \\
\hline
\end{tabular}

Tabel 8. Pengujian Halaman Universitas

Tujuan: Mengetahui fungsionalitas pada halaman Universitas

\begin{tabular}{cccc}
\multicolumn{4}{c}{ Tujuan: Mengetahui fungsionalitas pada halaman Universitas } \\
\hline No & Proses & Hasil yang diharapkan & Status \\
\hline 1 & $\begin{array}{c}\text { Click menu "Info } \\
\text { dashboard } \\
\text { universitas" }\end{array}$ & $\begin{array}{c}\text { Tampil halaman info dashboard } \\
\text { universitas }\end{array}$ & Success \\
& $\begin{array}{c}\text { Click menu } \\
\text { "Dashboard fakultas" } \\
\text { Click menu "Data } \\
\text { borang" }\end{array}$ & $\begin{array}{c}\text { Tampil halaman dashboard per fakultas } \\
\text { Tampil halaman data borang semua }\end{array}$ & Success \\
prodi & Succes \\
4 & Click tombol logout & Melakukan logout & Success \\
\hline
\end{tabular}

\section{Kesimpulan}

Berdasarkan hasil pembuatan system dashboard akreditasi perguruan tinggi standar 4 berbasis Key Performance Indicator maka dapat disimpulkan bahwa sistem yang dibangun adalah sistem dashboard akreditasi berbasis web yang dapat membantu operator prodi, operator fakultas dan operator universitas untuk menghadapi proses akreditasi. Pengujian menggunakan 
Black Box Testing menunjukkan bahwa hasil pembuatan sistem sesuai dengan kebutuhan yang ada serta menunjukkan keberhasilan sistem dalam melakukan login, lihat dashboard, upload data borang dan lihat data borang.

\section{Referensi}

[1] B. B. A. N. Pt, A. Prasetyo, and I. Widiyanto, "Sistem Panel Kinerja Untuk Program Studi Sarjana," vol. 01, pp. 13-17, 2013.

[2] P. R. Andriyani, I. Budiman, and R. A. Nugroho, "Aplikasi Dashboard Information System Performansi Akademik Perguruan Tinggi," pp. 27-39.

[3] E. Hariyanti, I. Werdiningsih, and K. Surendro, "Model Pengembangan Dashboard Untuk Monitoring Dan Evaluasi Kinerja Perguruan Tinggi."

[4] S. B. Standar, "Sistem dashboard untuk persiapan akreditasi program studi sarjana berdasarkan standar ban-pt," vol. 8, no. 1, pp. 871-882, 2016.

[5] S. Rahayu and B. M. Prasetyo, "Dashboard Information System," vol. 2012, no. semnasIF, pp. 82-87, 2012.

[6] J. S. Informasi, F. T. Informasi, I. Teknologi, S. Nopember, J. Arief, and R. Hakim, "Implementasi Metode Incremental Dalam Membangun," no. November, pp. 2-3, 2015.

[7] F. C. Saputro, W. Anggraeni, and A. Mukhlason, "Pembuatan Dashboard Berbasis Web Sebagai Sarana Evaluasi Diri Berkala Untuk Persiapan Penilaian Akreditasi Berdasarkan Standar Badan Akreditasi Nasional Perguruan Tinggi," J. Tek. ITS, vol. 1, no. 1, pp. A397A402, 2012.

[8] P. T. Sriwijaya, P. Indah, and P. Palembang, "Implementasi Incremental Model Pada Sistem Informasi Penyewaan Barang dan Jasa PT. Sriwijaya Indah Persada Palembang," vol. 06, no. $02,2016$. 